\title{
PRODUÇÃO DE DUAS ESPÉCIES DO GÊNERO Talinum EM FUNÇÃO DE DOSES DE COMPOSTO ORGÂNICO
}

\author{
Ricardo Ferreira Oliveira ${ }^{1}$, Adriano Jakelaitis ${ }^{2 *}$, Márcia Nara da Silva ${ }^{3}$, Leandro Spíndola \\ Pereira $^{4}$, José Weselli de Sá Andrade ${ }^{5}$, Gustavo Silva de Oliveira ${ }^{4}$, Gustavo Dorneles de \\ Sousa $^{4}$
}

\footnotetext{
${ }^{1}$ Mestre em Ciências Agrárias - Agronomia, Instituto Federal Goiano, Campus Rio Verde, Rio Verde-GO.

${ }^{2}$ Docente, Dr. em Fitotecnia, Instituto Federal Goiano, Campus Rio Verde, Rio Verde-GO. *E-mail do autor correspondente: adriano.jakelaitis@ifgoiano.edu.br.

${ }^{3}$ Doutora em Agronomia, Fitotecnia, Universidade Federal de Goiás, Goiânia-GO.

${ }^{4}$ Graduandos em Agronomia, Instituto Federal Goiano, Campus Rio Verde, Rio Verde-GO.

${ }^{5}$ Docente, Dr. em Agronomia, Fitotecnia, Instituto Federal Goiano, Campus Rio Verde, Rio Verde-GO.
}

Recebido: 07/11/2018; Aceito: 22/07/2019

RESUMO: Espécies do gênero Talinum apresentam folhas com importantes características nutricionais, o que favorece sua utilização para alimentação humana. $T$. triangulare e $T$. paniculatum são encontradas em todo Brasil como planta daninha, todavia nas regiões Norte, Nordeste e Centro-oeste são comercializadas como hortaliça não convencional. Objetivou-se, com este estudo, mensurar a produção de $T$. triangulare e $T$. paniculatum em função de doses de adubação de composto orgânico. Foram testados cinco níveis de adubação (0, 30, 60, 90 e 120 t ha $^{-1}$ de composto orgânico) mais uma testemunha, representada por adubação inorgânica na dose de $600 \mathrm{~kg} \mathrm{ha}^{-1}$ da formulação 04-14-08. Após o transplantio das mudas de ambas as espécies em canteiros foram feitas três colheitas, aos 50, 105 e 160 dias e para massa seca das folhas (MSF), de caule (MSC), de estrutura reprodutiva (MSER) e a parte aérea (MSPA) verificaram-se incrementos lineares às doses do adubo orgânico. Após o primeiro corte, as maiores doses de composto orgânico $\left(60,90\right.$, e $\left.120 \mathrm{t} \mathrm{ha}^{-1}\right)$ proporcionaram maior produção de folhas em relação à testemunha de adubação inorgânica. Foram encontradas correlações positivas e altamente significativas entre as variáveis altura de plantas (AP), número de folhas (NF), número de ramos (NR), MSF, MSC, MSER e MSPA. O efeito residual da adubação orgânica favorece a produção de hortaliças folhosas não convencionais.

Palavras-chave: Talinum triangulare. Talinum paniculatum. Hortaliças não convencionais. Cultivo orgânico.

\section{PRODUCTION OF TWO SPECIES OF THE GENUS Talinum AS A FUNCTION OF DOSES OF ORGANIC COMPOUND}

\begin{abstract}
Species of the genus Talinum present leaves with important nutritional characteristics, which favors their use for human consumption. $T$. triangulare and $T$. paniculatum are found throughout Brazil as weeds, however in the North, Northeast and Midwest regions they are marketed as unconventional vegetables. The objective of this study was to measure the production of $T$. triangulare and T. paniculatum as a function of organic
\end{abstract}


fertilization rates. Five levels of fertilization $\left(0,30,60,90\right.$ and $120 \mathrm{t} \mathrm{ha}^{-1}$ of organic compound) plus one control, represented by inorganic fertilization at the dose of $600 \mathrm{~kg} \mathrm{ha}^{-1}$ of formulation 04-14-08 were tested. After transplanting the seedlings of both species in beds, three harvests were made at 50, 105 and 160 days and for leaf dry matter (LDM), stem (SDM), reproductive structure (RSDM) and shoot (SHDM), there were linear increases in organic fertilizer doses. After the first cut, higher doses of organic compost $(60,90$, and $120 \mathrm{t}$ $\mathrm{ha}^{-1}$ ) provided higher leaf yield relative to the inorganic fertilization control. Positive and highly significant correlations were found among the variables height of plants (PH), number of leaves (NL), number of branches (NB), LDM, SDM, RSDM and SHDM. The residual effect of organic fertilization favors the production of unconventional leafy vegetables.

Key words: Talinum triangulare. Talinum paniculatum. Unconventional vegetables. Organic farming.

\section{INTRODUÇÃO}

Detentor de ampla biodiversidade vegetal, o Brasil possui espécies com grande potencial de uso, embora pouco conhecidas pela população em geral, a exemplo de Talinum triangulare e Talinum paniculatum, da família Talinaceae, que ocorrem em diversas regiões e ambientes (CARVALHO, 2013), infestando principalmente áreas cultivadas.

T. triangulare é provavelmente nativa da América ou África tropical e se adapta bem ao clima quente e úmido e a baixa fertilidade do solo (FASUYI, 2007; AGBONON et al., 2010; ALEXANDRE et al., 2018). Atualmente é cultivada na América do Sul, Ásia e África, especialmente na Nigéria e em outras regiões tropicais na África (AGBONON et al., 2010; UMEOKOLI et al., 2016).

T. paniculatum é nativa da América Latina e apresenta via fotossintética do metabolismo ácido C3/Crassuláceo (CAM) (PIETERS; TEZARA; HERRERA, 2003), com ampla distribuição em várias partes do mundo, devido a plasticidade fenotípica frente as diversidades ambientais. Ambas as espécies têm potencial tanto para consumo humano, por apresentarem importantes características nutricionais (ALEXANDRE et al., 2018), como para uso medicinal (THANAMOOL et al., 2013; REIS et al., 2015). No entanto, são restritas as informações científicas e técnicas pertinentes à sua produção.

Considerando que, na maioria das vezes, o consumo dessas plantas tenha por base principalmente folhas e caules, por meio de cortes até que haja capacidade de rebrota, a exigência de solos ricos em nutrientes é crucial para a manutenção da produção. Por esse motivo, o uso de fertilizantes orgânicos é uma alternativa para a melhoria da qualidade do solo em propriedades agrícolas que cultivam hortaliças (ZIECH et al. 2014; OLIVEIRA et al., 2014). Ademais, dependendo do seu grau de decomposição pode ter efeito imediato no solo pela melhor agregação e retenção de água, maior capacidade de troca catiônica (CTC) e pela disponibilidade de nutrientes (CANDIAN; MARTINS; CARDOSO, 2015; DINIZ et al., 2017). Além disto, há ainda os aspectos biológicos que estão relacionados com microrganismos benéficos encontrados na matéria orgânica (ZANDONADI et al., 2014). 
Apesar da importância do uso de compostos orgânicos na agricultura, em especial na produção de hortaliças, ainda são escassos os trabalhos desenvolvidos com hortaliças não convencionais. Assim, o objetivo desta pesquisa foi mensurar a produção hortícola de $T$. triangulare e T. paniculatum em função dos níveis de adubação de composto orgânico.

\section{MATERIAL E MÉTODOS}

Conduziu-se esta pesquisa no Setor de Olericultura do Instituto Federal Goiano (IF Goiano), Campus Rio Verde, Goiás, sob coordenadas geográficas de latitude 17\%48'55"S e longitude $50^{\circ} 56^{\prime} 28^{\prime \prime} \mathrm{O}$ e altitude de $753 \mathrm{~m}$, entre os meses de janeiro e julho de 2017. Segundo a classificação de Koppen e Geiger, o clima local é tropical (Aw). As precipitações variam de 1.500 a $1.800 \mathrm{~mm}$ anuais e ocorrem nos meses de outubro a maio, e os meses de seca estendem-se de junho a setembro. A variação da temperatura média anual é de 20 a $35^{\circ} \mathrm{C}$. A análise química e física do solo e do composto orgânico encontram-se na Tabela 1.

Tabela 1. Resumo das características químicas e físicas do solo da área experimental, na camada de $0-20 \mathrm{~cm}$ e do composto orgânico utilizado. Summary of the chemical and physical characteristics of the soil of the experimental area, in the layer of $0-20 \mathrm{~cm}$ and the organic compound tested.

\begin{tabular}{|c|c|c|c|c|c|c|c|c|}
\hline \multirow{2}{*}{ Descrição } & $\mathrm{pH}$ & $\mathrm{Ca}+\mathrm{Mg}$ & $\mathrm{Ca}$ & $\mathrm{Mg}$ & $\mathrm{Al}^{+3}$ & $\mathrm{H}+\mathrm{Al}$ & K & $\mathrm{P}$ \\
\hline & $\mathrm{CaCl}_{2}$ & \multicolumn{5}{|c|}{------------------ $\mathrm{cmol}_{\mathrm{c}} \mathrm{dm}^{-3}$------------------- } & \multicolumn{2}{|c|}{$--\mathrm{mg} \mathrm{dm}^{-3}--$} \\
\hline Solo $(0-20 \mathrm{~cm})$ & 4,3 & 2,8 & 2,2 & 0,6 & 0,2 & 5,8 & 41,0 & 124,1 \\
\hline \multirow[t]{3}{*}{ Composto Orgânico } & 6,6 & 7,1 & 2,6 & 4,5 & 0,0 & 1,4 & 1,8 & 94,4 \\
\hline & M.O. & C.O & \multicolumn{2}{|c|}{ CTC } & $\mathrm{Ca} / \mathrm{Mg}$ & $\mathrm{Ca} / \mathrm{K}$ & \multicolumn{2}{|c|}{$\mathrm{Mg} / \mathrm{K}$} \\
\hline & \multicolumn{2}{|c|}{------ $\mathrm{g} \mathrm{dm}^{-3}------$} & \multicolumn{2}{|c|}{$--\mathrm{cmol}_{\mathrm{c}} \mathrm{dm}^{-3}--$} & \multicolumn{4}{|c|}{------------ Relação ------------ } \\
\hline Solo $(0-20 \mathrm{~cm})$ & 34,8 & 20,2 & \multicolumn{2}{|l|}{8,7} & 3,5 & 21,0 & \multicolumn{2}{|c|}{6,2} \\
\hline \multirow[t]{3}{*}{ Composto Orgânico } & 85,1 & 49,4 & \multicolumn{2}{|l|}{8,5} & 0,6 & 0,0 & \multicolumn{2}{|c|}{0,0} \\
\hline & $\mathrm{K} / \mathrm{CTC}$ & $\mathrm{Ca} / \mathrm{CTC}$ & $\mathrm{Mg} / \mathrm{CTC}$ & $\mathrm{V}$ & $\mathrm{m}$ & Argila & Silte & Areia \\
\hline & \multicolumn{8}{|c|}{------------------------- Porcentagem (\%) ------------------------ } \\
\hline Solo $(0-20 c$ & 1,2 & 24,9 & 7,2 & 33,3 & 5,3 & 42,0 & 8,0 & 50,0 \\
\hline Composto Orgânico & 0,0 & 30,8 & 52,4 & 83,2 & 0,0 & 34,0 & 12,0 & 54,0 \\
\hline
\end{tabular}

$\mathrm{Ca}=$ cálcio; $\mathrm{Mg}$ = magnésio; $\mathrm{Al}^{+3}=$ alumínio; $\mathrm{K}=$ potássio; $\mathrm{P}=$ fósforo; $\mathrm{M} . \mathrm{O}$. = matéria orgânica; $\mathrm{C} . \mathrm{O} .=$ Carbono orgânico; $\mathrm{CTC}=$ Capacidade de troca de cátions $\mathrm{V}=$ Saturação por bases; $\mathrm{m}=$ Saturação por $\mathrm{Al}^{+3} \cdot \mathrm{Ca}$ = calcium $; \mathrm{Mg}=$ magnesium $; \mathrm{Al}^{+3}=$ aluminum $\mathrm{K}=$ potassium $; P=$ phosphorus; $M . O .=$ organic matter C.O. $=$ Organic carbon; $C T C=$ Cation exchange capacity $V=$ Base saturation; $m=$ Saturation by $\mathrm{Al}^{+3}$.

As sementes das espécies de $T$. triangulare e de $T$. paniculatum foram obtidas de biótipos que compõem a vegetação nativa que infesta o campo experimental do IF Goiano, campus Rio Verde. Inicialmente, as sementes colhidas foram processadas e postas para germinar na profundidade de $0,5 \mathrm{~cm}$ em bandejas de isopor de 288 células, utilizando o substrato comercial Bioplant ${ }^{\circledR}$ e cobertura com vermiculita. As bandejas foram mantidas em estufa específica para produção de mudas e, após a emergência, quando as plântulas apresentavam seis folhas expandidas, aos 30 dias após a semeadura, as mudas foram transplantadas para os canteiros. 
O ensaio foi implantado em dois canteiros em campo aberto, um para cada espécie. Cada canteiro apresentou dimensões de 1x24 metros, subdivididos em quatros blocos casualizados de seis metros. O espaçamento adotado foi de $0,25 \times 0,25 \mathrm{~m}$ entre plantas, totalizando 16 plantas por parcela. Os canteiros foram feitos com enxada rotativa e, por ocasião desta operação, foi feita a aplicação dos tratamentos.

Os tratamentos constaram de cinco dosagens de composto orgânico curtido $(0 ; 30 ; 60$; 90 e $\left.120 \mathrm{t} \mathrm{ha}^{-1}\right)$ mais um tratamento testemunha com adubação inorgânica (600 kg ha-1 de formulação 04-14-08). Aos 20 dias após transplantio (DAT) foi aplicada a adubação de cobertura no tratamento controle, utilizando $30 \mathrm{~kg} \mathrm{ha}^{-1}$ de $\mathrm{N}$, aplicado na forma de ureia. $\mathrm{O}$ composto orgânico foi obtido pela decomposição por 60 dias da mistura de resto de silagem de milho e esterco bovino, na proporção de 1:1.

Durante o cultivo, foram feitas duas capinas manuais aos 30 e 60 DAT. Foram feitos três cortes em plena floração para ambas as espécies. Para cada época de coleta, foram colhidas as quatro plantas centrais dentro de cada parcela, sendo o corte feito na região do colo e obtidas as seguintes variáveis resposta: altura das plantas (AP, em $\mathrm{cm}$ ), número de folhas (NF), número de ramos (NR) e massa seca das folhas (MSF, em g planta ${ }^{-1}$ ), caule $\left(\mathrm{MSC}\right.$, em g planta $\left.{ }^{-1}\right)$, estrutura reprodutiva (MSER, em g planta ${ }^{-1}$ ) e parte aérea (MSPA, em $g$ planta $\left.^{-1}\right)$.

A obtenção da altura das plantas foi feita por uma régua graduada. Depois de medidas, os materiais amostrados foram separados em folhas, caule e estrutura reprodutiva e, em seguida, levados para estufa com ventilação forçada a $70^{\circ} \mathrm{C}$, por 72 horas, até atingir massa constante, quando o material foi pesado em balança de precisão. Para a contagem das folhas, foram consideradas aquelas completamente expandidas.

Os resultados foram submetidos à análise de variância por meio do aplicativo estatístico GENES $^{\circledR}$ (CRUZ, 2013). A regressão com uso do Sigmaplot ${ }^{\circledR}$ foi utilizada para as cinco doses de composto orgânico, e o teste de Dunnett foi feito para comparar as médias das doses de composto orgânico contra a adubação inorgânica. Aplicou-se também a análise de correlação de Pearson entre as variáveis respostas. O nível de significância dos testes foi de $5 \%$.

\section{RESULTADOS E DISCUSSÃO}

A aplicação do composto orgânico aumentou linearmente a AP de T. triangulare quando as avaliações foram feitas aos 105 e aos 160 DAT, com acréscimos de 0,07 e 0,03 cm por $\mathrm{t} \mathrm{ha}^{-1}$ de composto orgânico adicionado aos canteiros, respectivamente (Tabela 2) e AP máxima de $35 \mathrm{~cm}$. Comparado a adubação mineral, as plantas adubadas com doses inferiores a $60 \mathrm{t} \mathrm{ha}^{-1}$ de composto produziram plantas de menor porte, cujo efeito foi superado após o primeiro corte, nas avaliações realizadas aos 105 e aos 160 DAT. Neste caso, as adubações feitas com doses acima de $90 \mathrm{t} \mathrm{ha}^{-1}$ produziram plantas mais altas (Tabela 2). Estes resultados corroboram com Vasconcelos et al. (2017) que avaliaram o efeito de doses de esterco de ovino no crescimento de alface e encontraram resposta linear para AP e efeito residual da aplicação na dose de $60 \mathrm{t} \mathrm{ha}^{-1}$. Cultivada como hortaliça não convencional na região de Rio Verde, GO, Alexandre et al. (2018) verificaram que T. triangulare atingiu uma AP variando 
de 41 a $57 \mathrm{~cm}$ quando cultivada a pleno sol e a $50 \%$ de sombreamento, sendo que a pleno sol a AP apresentou valores próximos aos encontrados no presente trabalho.

Tabela 2. Médias e equações estimadas das variáveis de altura de plantas (AP), número de folhas (NF) e número de ramos (NR) de plantas de Talinum triangulare avaliadas aos 50, 105 e 160 dias após o transplantio (DAT) em função das doses de 0, 30, 60, 90, e $120 \mathrm{t} \mathrm{ha}^{-1}$ de composto orgânico e de adubação inorgânica (AI). Means and estimated equations of plant height (AP), leaf number (NF) and number of branches (NR) of Talinum triangulare plants evaluated at 50, 105 and 160 days after transplanting (DAT) as a function of the doses of 0 , 30, 60, 90, and $120 \mathrm{th} \mathrm{h}^{-1}$ of organic compound and inorganic fertilization (AI).

\begin{tabular}{|c|c|c|c|c|c|c|c|c|c|}
\hline \multirow{2}{*}{ Variáveis } & \multirow{2}{*}{$\begin{array}{l}\text { Cortes } \\
\text { (DAT) }\end{array}$} & \multicolumn{5}{|c|}{ Composto orgânico $\left(\mathrm{t} \mathrm{ha}^{-1}\right)$} & \multirow{2}{*}{ AI } & \multirow{2}{*}{ Regressão } & \multirow{2}{*}{$\mathrm{R}^{2}$} \\
\hline & & 0 & 30 & 60 & 90 & 120 & & & \\
\hline \multirow{3}{*}{$\begin{array}{c}\text { AP } \\
(\mathrm{cm})\end{array}$} & 50 & $18^{-}$ & $20^{-}$ & $24^{-}$ & 28 & 24 & 29 & $\hat{\mathrm{Y}}=22,8$ & - \\
\hline & 105 & 24 & 29 & 30 & $35^{+}$ & $33^{+}$ & 24 & $\hat{Y}=25,6560+0,07 x$ & $0,82 *$ \\
\hline & 160 & 26 & 27 & 28 & $30^{+}$ & $33^{+}$ & 24 & $\hat{\mathrm{Y}}=25,8980+0,027 \mathrm{x}$ & $0,94 *$ \\
\hline \multirow{3}{*}{ NF } & 50 & $74^{-}$ & $98^{-}$ & $104^{-}$ & $130^{-}$ & $125^{-}$ & 177 & $\hat{Y}=79,21+0,4488 x$ & $0,89^{*}$ \\
\hline & 105 & 172 & 222 & $321^{+}$ & $384^{+}$ & $394^{+}$ & 201 & $\hat{\mathrm{Y}}=177,61+2,0173 \mathrm{x}$ & $0,94 *$ \\
\hline & 160 & 161 & $275^{+}$ & $287^{+}$ & $311^{+}$ & $395^{+}$ & 181 & $\hat{Y}=185,01+1,684 x$ & $0,90 *$ \\
\hline \multirow{3}{*}{ NR } & 50 & $5^{-}$ & $8^{-}$ & $9^{-}$ & $10^{-}$ & $11^{-}$ & 16 & $\hat{\mathrm{Y}}=6,188+0,5262 \mathrm{x}$ & $0,91^{*}$ \\
\hline & 105 & 19 & 23 & 30 & $39^{+}$ & $40^{+}$ & 22 & $\hat{Y}=18,55+0,196 x$ & $0,95^{*}$ \\
\hline & 160 & 24 & 35 & 34 & 40 & 54 & 44 & $\hat{Y}=24,602+0,214 x$ & $0,89 *$ \\
\hline
\end{tabular}

$\mathrm{AI}$ - testemunha com adubação inorgânica $\left(600 \mathrm{~kg} \mathrm{ha}^{-1}\right.$ de formulação 04-14-08 de plantio $+30 \mathrm{~kg} \mathrm{ha}^{-1} \mathrm{de} \mathrm{N} \mathrm{em}$ cobertura aos $20 \mathrm{DAT}) .+$ ou - representa média superior ou inferior, respectivamente, à testemunha comparativa (AI), pelo teste de Dunnett $(\mathrm{p}<0,05) . \mathrm{R}^{2}$, coeficiente de determinação. * significativo $(\mathrm{p}<0,05)$. ns não significativo (p>0,05). AI - control with inorganic fertilization (600 $\mathrm{kg} \mathrm{ha}^{-1}$ of formulation 04-14-08 of sowing + $30 \mathrm{~kg} \mathrm{ha}^{-1}$ of $N$ in topdressing at $\left.20 \mathrm{DAT}\right)$. + or - represents the upper or lower mean, respectively, for control $(A I)$, by Dunnett's test $(p<0.05) . R^{2}$, coefficient of determination. ${ }^{*}$ significant $(p<0.05) . n$ s non-significant $(p>0.05)$.

Os NF e NR aumentaram com a adição do composto orgânico em avaliações realizadas aos 50 DAT para $T$. triangulare, todavia, os valores médios situaram-se abaixo da testemunha fertilizada com adubo mineral (Tabela 2). A produção significativa de folhas ocorreu após o primeiro corte aos 105 DAT e aos 160 DAT com acréscimos de 2,0 e 1,68 folhas por planta para cada $\mathrm{t} \mathrm{ha}^{-1}$ de composto fornecido e o efeito residual do composto foi verificado após o primeiro corte em doses acima de $60 \mathrm{t} \mathrm{ha}^{-1}$. A partir do primeiro corte, o NR também aumentou linearmente com adição do composto em ambas as avaliações (105 e 160 DAT), sendo significativamente superior à adubação inorgânica avaliada aos 105 DAT a partir das doses de $60 \mathrm{t} \mathrm{ha}^{-1}$ (Tabela 2).

Para $T$. paniculatum verificaram-se, de forma geral, que foram menores os efeitos nas variáveis AP, NF e NR em relação ao aumento das doses de composto em relação à $T$. triangulare (Tabela 3). T. paniculatum apresentou maior incremento em altura até os 50 DAT com aumento linear $\left(0,10 \mathrm{~cm}\right.$ por $\mathrm{t} \mathrm{ha}^{-1}$ de composto) em resposta à adição de composto orgânico (Tabela 3). Contudo, após o primeiro corte, estabilizou-se em altura na avaliação feita aos 105 DAT e com baixos incrementos lineares aos 160 DAT. 
Tabela 3. Médias e equações estimadas das variáveis de altura de plantas (AP), número de folhas (NF) e número de ramos (NR) de plantas de Talinum paniculatum avaliados aos 50, 105 e 160 dias após o transplantio (DAT) em função das doses de 0, 30, 60, 90, e $120 \mathrm{t} \mathrm{ha}^{-1}$ de composto orgânico e de adubação inorgânica (AI). Means and estimated equations of plant height (AP), leaf number (NF) and number of branches (NR) of Talinum paniculatum plants evaluated at 50, 105 and 160 days after transplanting (DAT) as a function of the doses of 0 , 30, 60, 90, and $120 \mathrm{tha}^{-1}$ of organic compound and inorganic fertilization (AI).

\begin{tabular}{|c|c|c|c|c|c|c|c|c|c|}
\hline \multirow[t]{2}{*}{ Variáveis } & \multirow{2}{*}{$\begin{array}{l}\text { Cortes } \\
\text { (DAT) }\end{array}$} & \multicolumn{5}{|c|}{ Composto orgânico $\left(\mathrm{t} \mathrm{ha}^{-1}\right)$} & \multirow{2}{*}{ AI } & \multirow{2}{*}{ Regressão } & \multirow{2}{*}{$\mathrm{R}^{2}$} \\
\hline & & 0 & 30 & 60 & 90 & 120 & & & \\
\hline \multirow{3}{*}{$\begin{array}{c}\text { AP } \\
(\mathrm{cm})\end{array}$} & 50 & $24^{-}$ & 33 & 33 & 36 & 37 & 43 & $\hat{\mathrm{Y}}=26,98+0,10 \mathrm{x}$ & 0,82 \\
\hline & 105 & 20 & 22 & 23 & 23 & $32^{+}$ & 20 & $\hat{Y}=24$ & - \\
\hline & 160 & 5 & 6 & 7 & $8^{+}$ & $9^{+}$ & 7 & $\hat{Y}=5,18+0,036 x$ & 0,96 \\
\hline \multirow{3}{*}{$\mathrm{NF}$} & 50 & $36^{-}$ & $37^{-}$ & $55^{-}$ & $60^{-}$ & $57^{-}$ & 76 & $\hat{\mathrm{Y}}=36,00+0,2194 \mathrm{x}$ & 0,80 \\
\hline & 105 & $36^{-}$ & 52 & 88 & $115^{+}$ & $104^{+}$ & 71 & $\hat{Y}=39,2+0,6633 x$ & 0,86 \\
\hline & 160 & 35 & 49 & 66 & $80^{+}$ & $108^{+}$ & 44 & $\hat{Y}=33,006+0,58 x$ & 0,98 \\
\hline \multirow{3}{*}{ NR } & 50 & $4^{-}$ & $4^{-}$ & $5^{-}$ & 7 & 7 & 8 & $\hat{\mathrm{Y}}=4,01+0,03 \mathrm{x}$ & 0,86 \\
\hline & 105 & 6 & 7 & 11 & 13 & 14 & 10 & $\hat{\mathrm{Y}}=5,84+0,07 \mathrm{x}$ & 0,90 \\
\hline & 160 & 5 & 7 & 8 & 9 & $13^{+}$ & 8 & $\hat{Y}=4,91+0,06 x$ & 0,93 \\
\hline
\end{tabular}

$\mathrm{AI}$ - testemunha com adubação inorgânica $\left(600 \mathrm{~kg} \mathrm{ha}^{-1}\right.$ de formulação 04-14-08 de plantio $+30 \mathrm{~kg} \mathrm{ha}^{-1} \mathrm{de} \mathrm{N} \mathrm{em}$ cobertura aos 20DAT) + ou - representa média superior ou inferior, respectivamente, à testemunha comparativa $(\mathrm{AI})$, pelo teste de Dunnet $(\mathrm{p}<0,05) . \mathrm{R}^{2}$, coeficiente de determinação. * significativo $(\mathrm{p}<0,05)$. ns não significativo (p>0,05). AI - control with inorganic fertilization (600 $\mathrm{kg} \mathrm{ha}^{-1}$ of formulation 04-14-08 of sowing + $30 \mathrm{~kg} \mathrm{ha}^{-1}$ of $\mathrm{N}$ in topdressing to 20DAT). + or - represents the upper or lower mean, respectively, for the comparative control $(A I)$, by the Dunnet test $(p<0.05)$. $R^{2}$, coefficient of determination. * significant $(p<0.05)$. ns non-significant ( $p>0.05)$.

Para NF e NR os melhores ajustes encontrados para T. paniculatum em função das doses foram os lineares crescentes. As respostas lineares de T. paniculatum às doses do composto orgânico em relação a $T$. triangulare foram caracterizadas por menores coeficientes angulares e pelo menor número de contrastes significativos quando comparado às testemunhas fertilizadas com adubação mineral (Tabelas 2 e 3). Evidencia-se, desta forma, que plantas do gênero Talinum, como T. paniculatum e T. triangulare, não requererem solos com elevados teores de matéria orgânica ou de nutrientes, característica da maioria dos solos brasileiros, para sua sobrevivência, visto que têm se tornado plantas infestantes de campos agrícolas (CARVALHO, 2013) e de ambientes urbanos (MACHADO FILHO et al., 2015).

A produção de massa seca das diferentes partes das plantas de T. triangulare em função das doses de composto orgânico foi explicada por modelos lineares crescentes, com exceção da MSER avaliadas aos 160 DAT (Tabela 4). Para a MSF os maiores valores foram obtidos nas avalições realizadas aos 105 DAT com coeficiente angular de $0,1716 \mathrm{~g}$ planta, em relação aos coeficientes obtidos aos 50 DAT $(0,10)$ e aos 160 DAT $(0,1133)$, indicando que o efeito aditivo das doses do composto orgânico prevaleceram até os 160 DAT, o que torna a adubação orgânica uma ótima opção de cultivo para estas hortaliças folhosas não convencionais. Em relação à adubação inorgânica, as avaliações feitas aos 50 DAT denotaram que a MSF produzida mostrou-se igual à obtida pela adubação feita nas doses a partir de $90 \mathrm{t}$ 
ha $^{-1}$ de composto orgânico e que aos 105 e aos 160 DAT a adoção do manejo do solo com composto orgânico nas doses acima de $90 \mathrm{t} \mathrm{ha}^{-1}$ possibilitaram maior MSF (Tabela 4).

Tabela 4. Médias e equações estimadas das variáveis massa seca de folhas (MSF), de caule (MSC), de estrutura reprodutiva (MSER) e da parte aérea (MSPA) de plantas de Talinum triangulare avaliados aos 50, 105 e 160 dias após o transplantio (DAT) em função dos tratamentos 0, 30, 60, 90, e $120 \mathrm{t} \mathrm{ha}^{-1}$ de composto orgânico e de adubação inorgânica (AI). Means and estimated equations of leaf dry mass (MSF), stem (MSC), reproductive structure (MSER) and aerial part (MSPA) of Talinum triangulare plants evaluated at 50, 105 and 160 days (DAT) as a function of treatments 0, 30, 60, 90 and $120 \mathrm{th} \mathrm{h}^{-1}$ of organic compound and inorganic fertilization (AI).

\begin{tabular}{|c|c|c|c|c|c|c|c|c|c|}
\hline \multirow{2}{*}{ Variáveis } & \multirow{2}{*}{$\begin{array}{l}\text { Cortes } \\
\text { (DAT) }\end{array}$} & \multicolumn{5}{|c|}{ Composto orgânico $\left(\mathrm{t} \mathrm{ha}^{-1}\right)$} & \multirow{2}{*}{ AI } & \multirow{2}{*}{ Regressão } & \multirow{2}{*}{$\mathrm{R}^{2}$} \\
\hline & & 0 & 30 & 60 & 90 & 120 & & & \\
\hline \multirow{3}{*}{$\begin{array}{c}\text { MSF } \\
\text { (g por planta) }\end{array}$} & 50 & $6,9^{-}$ & $12,4^{-}$ & $14,0^{-}$ & 18,1 & 18,6 & 21,6 & $\hat{\mathrm{Y}}=8,21+0,10 \mathrm{x}$ & $0,93 *$ \\
\hline & 105 & 12,0 & 19,3 & 23,7 & $30,4^{+}$ & $32,1^{+}$ & 15,4 & $\hat{Y}=13,20+0,1716 x$ & $0,96 *$ \\
\hline & 160 & 11,6 & 19,6 & 22,6 & $24,7^{+}$ & $26,0^{+}$ & 13,7 & $\hat{Y}=14,10+0,1133 x$ & $0,87 *$ \\
\hline \multirow{3}{*}{$\begin{array}{c}\text { MSC } \\
\text { (g por planta) }\end{array}$} & 50 & $1,2^{-}$ & $2,5^{-}$ & $3,8^{-}$ & $5,5^{-}$ & $5,2^{-}$ & 8,3 & $\hat{\mathrm{Y}}=1,49+0,04 \mathrm{x}$ & $0,92 *$ \\
\hline & 105 & 7,3 & 9,6 & $15,2^{+}$ & $23,2^{+}$ & $23,8^{+}$ & 7,2 & $\hat{Y}=6,46+0,16 x$ & $0,95^{*}$ \\
\hline & 160 & 16,5 & $30,5^{+}$ & $36,1^{+}$ & $38,4^{+}$ & $59,9^{+}$ & 23,3 & $\hat{Y}=17,35+0,32 x$ & $0,91 *$ \\
\hline \multirow{3}{*}{$\begin{array}{c}\text { MSER } \\
\text { (g por planta) }\end{array}$} & 50 & $0,3^{-}$ & $0,5^{-}$ & $0,6^{-}$ & 1,2 & 1,1 & 1,4 & $\hat{\mathrm{Y}}=0,28+0,01 \mathrm{x}$ & $0,89 *$ \\
\hline & 105 & 2,4 & $4,4^{+}$ & $4,6^{+}$ & $6,9^{+}$ & $7,6^{+}$ & 2,2 & $\hat{Y}=2,62+0,04 x$ & $0,95^{*}$ \\
\hline & 160 & 2,6 & 3,3 & 4,3 & 3,4 & $4,9^{+}$ & 2,9 & $\hat{\mathrm{Y}}=3,7$ & - \\
\hline \multirow{3}{*}{$\begin{array}{c}\text { MSPA } \\
\text { (g por planta) }\end{array}$} & 50 & $8,5^{-}$ & $15,4^{-}$ & $18,4^{-}$ & $24,7^{-}$ & $24,9^{-}$ & 31,3 & $\hat{\mathrm{Y}}=10,01+0,14 \mathrm{x}$ & $0,94 *$ \\
\hline & 105 & 21,6 & 33,3 & $43,5^{+}$ & $60,6^{+}$ & $63,6^{+}$ & 24,8 & $\hat{\mathrm{Y}}=22,28+0,37 \mathrm{x}$ & $0,97 *$ \\
\hline & 160 & 30,7 & $53,4^{+}$ & $62,9^{+}$ & $66,6^{+}$ & $90,8^{+}$ & 39,8 & $\hat{\mathrm{Y}}=34,24+0,44 \mathrm{x}$ & $0,94 *$ \\
\hline
\end{tabular}

$\mathrm{AI}$ - testemunha com adubação inorgânica (600 $\mathrm{kg} \mathrm{ha}^{-1}$ de formulação 04-14-08 de plantio+30 $\mathrm{kg} \mathrm{ha}^{-1} \mathrm{de} \mathrm{N}$ em cobertura aos 20DAT). + ou - representa média superior ou inferior, respectivamente, à testemunha comparativa (AI), pelo teste de Dunnet $(\mathrm{p}<0,05)$. $\mathrm{R}^{2}$, coeficiente de determinação. * significativo ( $\left.\mathrm{p}<0,05\right) .{ }^{\mathrm{ns}}$ não significativo (p>0,05). AI - control with inorganic fertilization (600 $\mathrm{kg} \mathrm{ha}^{-1}$ of formulation 04-14-08 of sowing $+30 \mathrm{~kg} \mathrm{ha}^{-1}$ of $N$ in topdressing to 20DAT). + or - represents the upper or lower mean, respectively, for the comparative control $(A I)$, by the Dunnet test $(p<0.05) . R^{2}$, coefficient of determination. $*$ significant $(p<0.05) .{ }^{n s}$ nonsignificant $(p>0.05)$.

A produção de MSC aumentou 0,04, 0,16 e 0,32 g por planta para cada $\mathrm{t} \mathrm{ha}^{-1}$ de composto adicionado em avaliações realizadas aos 50, 105 e 160 DAT, respectivamente (Tabela 4). O benefício da adubação inorgânica na MSC foi evidenciado na avaliação feita aos 50 DAT com produção superior ao composto orgânico. Porém, após os 50 DAT nas avaliações realizadas aos 105 DAT a partir da dose de $60 \mathrm{t} \mathrm{ha}^{-1}$ de composto orgânico e aos 160 DAT a partir da dose de $30 \mathrm{t} \mathrm{ha}^{-1}$ observaram-se maiores MSC nas plantas de $T$. triangulare, quando comparado as plantas tratadas com a adubação inorgânica. Estas respostas da MSC em relação aos tratamentos assemelharam-se aos observados para MSPA (Tabela 4). Já, para a MSER os melhores resultados foram observados nas avaliações feitas aos 105 DAT com aumentos lineares e produção superior a adubação inorgânica a partir da dose de $30 \mathrm{t} \mathrm{ha}^{-1}$ de composto orgânico (Tabela 4). Assim, para T. triangulare, a adubação 
inorgânica não proporcionou efeito residual sobre as variáveis de produção, demonstrando resultados semelhantes aos retratados por Santos et al. (2001) com alface.

Em relação as produções de massa seca de T. paniculatum em função do composto orgânico foram observadas respostas lineares crescentes para MSF, MSC, MSER e MSPA, com maiores coeficientes angulares aos 105 DAT, com 0,10; 0,11; 0,11; e 0,31 g por planta, respectivamente, para cada $\mathrm{tha}^{-1}$ de composto usado (Tabela 5). Aos 50 DAT, observaram-se menores valores de massa seca para as doses de composto orgânico em relação à adubação inorgânica. Já, aos 105 DAT para as doses de composto orgânico superior a $90 \mathrm{t} \mathrm{ha} \mathrm{ha}^{-1}$ obtiveram-se maiores acúmulos de MSF, MSC e MSPA e para MSER superior a $60 \mathrm{t} \mathrm{ha}^{-1}$. Aos $160 \mathrm{DAT}$, os resultados mostram que, ao incorporar pelo menos $60 \mathrm{t} \mathrm{ha}^{-1}$ ao solo, são alcançadas melhores respostas de MSC, MSER e MSPA, enquanto a produção de MSF permanece constante na dose de $60 \mathrm{t} \mathrm{ha}^{-1}$ (Tabela 5).

Respostas lineares para os componentes de produção foram reportados por Lanna et al. (2018) ao confirmarem efeito residual da adubação com composto orgânico na produção de rabanete. Para Salles et al. (2017), a adubação orgânica contendo esterco de aves aplicado de forma isolada ou em mistura com outros compostos proporcionou maior produtividade da cultura da rúcula. Para o cultivo orgânico de hortaliças, a dose de $40 \mathrm{t} \mathrm{ha}^{-1}$ incorporada ao solo foi a melhor opção, tendo em vista a liberação mais lenta dos nutrientes no solo em relação aos fertilizantes inorgânicos (SEDIYAMA et al., 2016).

A produção de hortaliças folhosas requer solos ricos em nutrientes, respondendo particularmente à adubação orgânica. A adição de adubos orgânicos em solos de clima tropical, em que a mineralização da matéria orgânica é intensa torna-se imperativo para evitar as perdas na quantidade e na qualidade da matéria orgânica do solo, com consequente redução da produtividade (MONTEMURRO et al., 2010; SEDIYAMA et al., 2016). Para alface foi confirmado os efeitos benéficos da adição de composto orgânico com aumento na massa e nos teores de nutrientes (ABREU et al. 2010; SHAHEIN; AFIFI; ALGHARIB, 2014), sendo encontrado valores superiores a $40 \%$ na produtividade, em comparação ao controle (SEDIYAMA et al., 2016). Desta forma, o efeito residual da matéria orgânica adicionada pode ocorrer a longo prazo sobre culturas cultivadas em sucessão (DINIZ et al. 2017; LANNA et al. 2018) ou a médio e pequeno prazo sobre a cultura implantada após a adição do composto (CANDIAN; MARTINS; CARDOSO, 2015; SILVA et al. 2015), conforme observados no acúmulo de massa nas plantas de $T$. triangulare e $T$. paniculatum (Tabelas 4 a $5)$. 
Tabela 5. Médias e equações estimadas das variáveis massa seca de folhas (MSF), de caule (MSC), de estrutura reprodutiva (MSER) e da parte aérea (MSPA) de plantas de Talinum paniculatum avaliados aos 50, 105 e 160 dias após o transplantio (DAT) em função dos tratamentos $0,30,60,90$, e $120 \mathrm{t} \mathrm{ha}^{-1}$ de composto orgânico e de adubação inorgânica (AI). Means and estimated equations of leaf dry mass (MSF), stem (MSC), reproductive structure (MSER) and aerial part (MSPA) of Talinum paniculatum plants evaluated at 50, 105 and 160 days (DAT) as a function of treatments 0, 30, 60, 90 and $120 \mathrm{th} \mathrm{h}^{-1}$ of organic compound and inorganic fertilization (AI).

\begin{tabular}{|c|c|c|c|c|c|c|c|c|c|}
\hline \multirow{2}{*}{ Variáveis } & \multirow{2}{*}{$\begin{array}{l}\text { Cortes } \\
\text { (DAT) }\end{array}$} & \multicolumn{5}{|c|}{ Composto orgânico $\left(\mathrm{t} \mathrm{ha}^{-1}\right)$} & \multirow{2}{*}{$\mathrm{AI}$} & \multirow{2}{*}{ Equação estimada $(S f)$} & \multirow{2}{*}{$\mathrm{R}^{2}$} \\
\hline & & 0 & 30 & 60 & 90 & 120 & & & \\
\hline \multirow{3}{*}{$\begin{array}{c}\text { MSF } \\
\text { (g por planta) }\end{array}$} & 50 & $4,0^{-}$ & $4,8^{-}$ & $8,1^{-}$ & $8,4^{-}$ & $10,3^{-}$ & 13,7 & $\hat{\mathrm{Y}}=3,90+0,05 \mathrm{x}$ & $0,94 *$ \\
\hline & 105 & $4,7^{-}$ & 6,7 & 9,6 & $14,9^{+}$ & $15,9^{+}$ & 8,7 & $\hat{\mathrm{Y}}=4,26+0,10 \mathrm{x}$ & $0,96^{*}$ \\
\hline & 160 & 7,2 & 8,2 & 11,6 & $14,9^{+}$ & $19,5^{+}$ & 9,5 & $\hat{\mathrm{Y}}=6,01+0,11 \mathrm{x}$ & $0,96^{*}$ \\
\hline \multirow{3}{*}{$\begin{array}{c}\text { MSC } \\
\text { (g por planta) }\end{array}$} & 50 & $1,1^{-}$ & $1,6^{-}$ & $2,7^{-}$ & $3,0^{-}$ & $4,7^{-}$ & 7,3 & $\hat{Y}=0,89+0,03 x$ & $0,95^{*}$ \\
\hline & 105 & 1,9 & 3,9 & 8,0 & $10,9^{+}$ & $15,0^{+}$ & 5,8 & $\hat{\mathrm{Y}}=1,29+0,11 \mathrm{x}$ & $0,98^{*}$ \\
\hline & 160 & 2,8 & 2,3 & $4,6^{+}$ & $5,2^{+}$ & $9,2^{+}$ & 2,1 & $\hat{Y}=1,68+0,05 x$ & $0,83^{*}$ \\
\hline \multirow{3}{*}{$\begin{array}{c}\text { MSER } \\
\text { (g por planta) }\end{array}$} & 50 & $0,5^{-}$ & $1,8^{-}$ & $2,1^{-}$ & $2,8^{-}$ & $4,4^{-}$ & 5,7 & $\hat{Y}=0,57+0,03 x$ & $0,94 *$ \\
\hline & 105 & 1,2 & 3,9 & $5,5^{+}$ & $9,3^{+}$ & $14,3^{+}$ & 2,9 & $\hat{\mathrm{Y}}=0,57+0,11 \mathrm{x}$ & $0,96^{*}$ \\
\hline & 160 & $3,9^{+}$ & 2,5 & $3,9^{+}$ & $7,8^{+}$ & $13,4^{+}$ & 2,3 & $\hat{\mathrm{Y}}=1,44+0,081 \mathrm{x}$ & $0,75^{*}$ \\
\hline \multirow{3}{*}{$\begin{array}{c}\text { MSPA } \\
\text { (g por planta) }\end{array}$} & 50 & $5,6^{-}$ & $8,3^{-}$ & $12,8^{-}$ & $14,2^{-}$ & $19,4^{-}$ & 26,8 & $\hat{Y}=5,358+0,112 x$ & $0,98^{*}$ \\
\hline & 105 & $7,9^{-}$ & 14,5 & 23,1 & $35,2^{+}$ & $45,2^{+}$ & 17,5 & $\hat{Y}=6,124+0,3179 x$ & $0,98^{*}$ \\
\hline & 160 & 13,9 & 13,0 & $20,2^{+}$ & $27,8^{+}$ & $42,2^{+}$ & 13,9 & $\hat{Y}=39,2+0,238 x$ & $0,89^{*}$ \\
\hline
\end{tabular}

$\mathrm{AI}$ - testemunha com adubação inorgânica (600 $\mathrm{kg} \mathrm{ha}^{-1}$ de formulação 04-14-08 de plantio+30 kg ha ${ }^{-1} \mathrm{de} \mathrm{N} \mathrm{em}$ cobertura aos 20DAT) + ou - representa média superior ou inferior, respectivamente, à testemunha comparativa $(\mathrm{AI})$, pelo teste de Dunnet $(\mathrm{p}<0,05) \cdot \mathrm{R}^{2}$, coeficiente de determinação. * significativo $(\mathrm{p}<0,05)$. ${ }^{\text {ns }}$ não significativo (p>0,05). AI - control with inorganic fertilization (600 kg ha-l of formulation 04-14-08 of sowing $+30 \mathrm{~kg} \mathrm{ha}^{-1}$ of $N$ in topdressing to 20DAT). + or - represents the upper or lower mean, respectively, for the comparative control (AI), by the Dunnet test $(p<0.05) . R^{2}$, coefficient of determination. ${ }^{*}$ significant $(p<0.05) .{ }^{n s}$ nonsignificant $(p>0.05)$.

Correlações positivas e altamente significativas entre as variáveis resposta foram encontradas para ambas as espécies, com valores do coeficiente de correlação " $r$ " superiores a 0,90 e a 0,88 para $T$. triangulare e $T$. paniculatum, respectivamente (Tabela 6). Assim, percebe-se que as plantas avaliadas apresentaram maiores AP, NF, NR, MSF, MSC, MSEF e MSPA com o aumento das doses do composto orgânico, apresentando crescimento equilibrado das diferentes partes mensuradas. A relação linear de cada variável na MSPA, considerando que o consumo de $T$. triangulare e $T$. paniculatum é principalmente de folhas e caules, torna-se necessária em função da resposta às doses de composto orgânico. Diniz et al. (2008) avaliando o crescimento e a produção de brócolis em função de doses de composto orgânico observaram que a área do dossel, o comprimento da folha e a massa seca foram as variáveis com maior correlação com a produção. No cultivo do feijão-vagem em função de doses de esterco de galinha, bovino e caprino, Santos et al. (2001) relataram correlação significativa positiva entre o comprimento e o rendimento de vagens $\left(0,84^{* *}\right)$ e baixo valor 
para a correlação entre o rendimento e o peso médio de vagens $\left(0,42^{*}\right)$, indicando que o rendimento foi função do comprimento de vagens.

Tabela 6. Coeficientes de correlação de Pearson entre as variáveis submetidas à dosagem de composto orgânico. Acima da diagonal refere-se a Talinum triangulare e abaixo da diagonal Talinum paniculatum. Pearson correlation coefficients among the variables submitted to the dosage of organic compound. Above the diagonal refers to Talinum triangulare and below the diagonal Talinum paniculatum).

\begin{tabular}{|c|c|c|c|c|c|c|c|}
\hline Variáveis & $\mathrm{AP}$ & $\mathrm{NF}$ & NR & MSF & MSC & MSEF & MSPA \\
\hline AP & - & $0,96^{* *}$ & $0,92 *$ & $0,97 * *$ & $0,90 *$ & $0,93^{*}$ & $0,94 *$ \\
\hline NF & $0,90 *$ & - & $0,98 * *$ & $0,99 * *$ & $0,98 * *$ & $0,99 * *$ & $0,99 * *$ \\
\hline NR & $0,94 *$ & $0,98 * *$ & - & $0,96 * *$ & $0,99 * *$ & $0,99 * *$ & $0,99 * *$ \\
\hline MSF & $0,93 *$ & $0,98 * *$ & $0,99 * *$ & - & $0,95 * *$ & $0,97 * *$ & $0,98 * *$ \\
\hline MSC & $0,94 *$ & $0,94 *$ & $0,98 * *$ & $0,98 * *$ & - & $0,99 * *$ & $0,99 * *$ \\
\hline MSEF & $0,93^{*}$ & $0,88^{*}$ & $0,95 * *$ & $0,96 * *$ & $0,97 * *$ & - & $0,99 * *$ \\
\hline MSPA & $0,94^{*}$ & $0,94 *$ & $0,99 * *$ & $0,99 * *$ & $0,99 * *$ & $0,98 * *$ & - \\
\hline
\end{tabular}

AP: altura de plantas; NF: números de folhas; NR: número de ramos; MSF: massa seca das folhas; MSC: massa seca do caule; MSER: massa seca das estruturas reprodutivas; MSPA: massa seca da parte aérea. * e ** Significativo a 1 e $5 \%$ de probabilidade pelo o teste t respectivamente. AP: plant height; NF: leaf numbers; NR: number of branches; MSF: leaf dry matter; MSC: stem dry mass; MSER: dry mass of reproductive structures; MSPA: shoot dry mass. * and ** Significant at 1 and 5\% probability by the test respectively.

\section{CONCLUSÃO}

A adubação inorgânica é uma opção adequada de manejo a curto prazo, e a médio e longo prazo, a utilização da adubação orgânica é a melhor opção pela capacidade de disponibilizar nutrientes de forma lenta.

De forma geral, as doses de composto orgânico acima de $60 \mathrm{t} \mathrm{ha}^{-1}$ garantem produtividade acima da testemunha fertilizada com adubo inorgânico.

Considerando a produção de folhas, no segundo e o terceiro corte obtém-se maior produção, principalmente adubadas com doses superiores a $30 \mathrm{t} \mathrm{ha}^{-1}$ de composto orgânico para ambas as espécies.

T. triangulare mostrou-se mais produtiva em relação a $T$. paniculatum, quando submetidas aos mesmos tratamentos.

\section{AGRADECIMENTOS}

À Coordenação de Aperfeiçoamento de Pessoal de Nível Superior - Brasil (CAPES) Código de Financiamento 001, e ao IF Goiano pelo apoio financeiro. 


\section{REFERÊNCIAS BIBLIOGRÁFICAS}

ABREU, I. M. O.; JUNQUEIRA, A. M. R.; PEIXOTO, J. R.; OLIVEIRA, S. A. Qualidade microbiológica e produtividade de alface sob adubação química e orgânica. Ciência e Tecnologia de Alimentos, Campinas, v. 30, n. 1, p.108-118, 2010. Disponível em: http://www.redalyc.org/html/3959/395940103018. Acesso em: 10 out. 2018.

AGBONON, A.; EKLU-GADEGBEKU, K.; AKLIKOKOU, K.; GBEASSOR, M.; AKPAGANA, K.; TAM, T. W.; ARNASON, J. T.; FOSTER, B. C. In vitro inhibitory effect of West African medicinal and food plants on human cytochrome $\mathrm{P}_{450} 3 \mathrm{~A}$ subfamily. Journal of Ethnopharmacology, Lausanne, v. 128, n. 2, p. 390-394, 2010. Disponível em: https://doi.org/10.1016/j.jep.2010.01.039. Acesso em: 03 out. 2018.

ALEXANDRE, E. F.; PEREIRA, L. S.; ANDRADE, J. W. S.; VASCONCELOS FILHO, S. C.; JAKELAITIS, A. Plant biometric characterization and leaf micromorphometry of Talinum triangulare (Jacq.) Willd cultivated under shade. Revista Ceres, Viçosa, v. 65, n. 1, p.44-55, 2018. Disponível em: http://www.scielo.br/pdf/rceres/v65n1/0034-737X-rceres-65-01-44.pdf. Acesso em: 10 out. 2018.

CANDIAN, J. A.; MARTINS, B. N. M.; CARDOSO, A. I. I. Doses de composto orgânico no desenvolvimento inicial de couve-flor e nas características químicas do solo. Revista Cultivando o Saber, Botucatu, v. 8, n. 3, p.257-266, 2015. Disponível em: https://www.fag.edu.br/upload/revista/cultivando_o_saber/564a5f1c0a89a.pdf. Acesso em: 20 out. 2018.

CARVAlHO, L. B. Classificações. In: CARVALHO, L. B. (ed.). Plantas daninhas. Lages: FAESB, 2013. cap. 5, p. 35-48.

CRUZ, C. D. GENES - a software package for analysis in experimental statistics and quantitative genetics. Acta Scientiarum Agronomy, Maringá, v. 35, n. 3, p.271-276, 2013. Disponível em: http://www.scielo.br/pdf/asagr/v35n3/v35n3a01.pdf. Acesso em: 20 out. 2018.

DINIZ, E. R.; SANTOS, R. H. S.; URQUIAGA, S. S.; PETERNELLI, L. A.; BARRELLA, T. P.; FREITAS, G. D. Crescimento e produção de brócolis em sistema orgânico em função de doses de composto. Ciência e Agrotecnologia, Lavras, v. 32, n. 5, p.1428-1434, 2008. Disponível em: http://www.scielo.br/pdf/cagro/v32n5/11.pdf. Acesso em: 15 jul. 2019.

DINIZ, E. R.; VARGAS, T. O.; GUEDES, A. F.; SANTOS, R. H. S.; URQUIAGA, S.; MODOLO, A. J. Doses of Crotalaria juncea: Residual effect on zucchini and maize crop in sequence to broccoli. Revista Ceres, Viçosa, MG, v. 64, n. 6, p.600-606, 2017. Disponível em: http://www.scielo.br/pdf/rceres/v64n6/0034-737X-rceres-64-06-600.pdf. Acesso em: 22 out. 2018.

FASUYI, A. O. Bio-nutritional evaluations of three tropical leaf vegetables (Telfairia occidentalis, Amaranthus cruentus and Talinum triangulare) as sole dietary protein sources in rat assay. Food Chemistry, Barking, v. 103, n. 3, p. 757-765, 2007. Disponível em: https://doi.org/10.1016/j.foodchem.2006.09.030. Acesso em: 05 out. 2018. 
LANNA, N. B. L.; SILVA, P. N. L.; COLOMBARI, L. F.; CORRÊA, C. V.; CARDOSO, A. I. I. Residual effect of organic fertilization on radish production. Horticultura Brasileira, Vitória da Conquista, v. 36, n. 1, p.47-53, 2018. Disponível em: http://www.scielo.br/pdf/hb/v36n1/1806-9991-hb-36-01-47.pdf. Acesso em: 08 out. 2018.

MACHADO FILHO, H.; COUTO, E. A.; BEZERRA, C. P.; MELO, J. I. M. Composition and similarity of flora associated with anthropogenic sites in the city of João Pessoa-Paraíba. Planta Daninha, Viçosa, MG, v. 33, n. 1, p.57-66, 2015. Disponível em: http://www.scielo.br/pdf/pd/v33n1/0100-8358-pd-33-01-00057.pdf. Acesso em: 08 out. 2018.

MONTEMURRO, F.; FERRI, D.; TITTARELlI, F.; CANALI, S.; VITTI, C. Anaerobic digestate and on-farm compost application: Effects on lettuce (Lactuca sativa L.) crop production and soil properties. Compost Science \& Utilization, Emmaus, v. 18, n. 3, p.184193, 2010. Disponível em: https://doi.org/10.1080/1065657X.2010.10736954. Acesso em: 18 out. 2018.

OLIVEIRA, L. B.; ACCIOLY, A. M. A.; SANTOS, C. L. R.; FLORES, R. A.; BARBOSA, F. S. Características químicas do solo e produção de biomassa de alface adubada com compostos orgânicos. Revista Brasileira de Engenharia Agrícola e Ambiental, Campina Grande, v. 18, n. 2, p.157-164, 2014. Disponível em: http://www.agriambi.com.br/revista/v18n02/v18n02a05.pdf. Acesso em: 08 out. 2018.

PIETERS, A. J.; TEZARA, W.; HERRERA, A. Operation of the xanthophyll cycle and degradation of D1 protein in the inducible CAM plant, Talinum triangulare, under water deficit. Annals of Botany, Oxford, v. 92, n. 3, p.393-399, 2003 Disponível em: https://doi.org/10.1093/aob/mcg153. Acesso em: 04 out. 2018.

REIS, L. F. C.; CERDEIRA, C. D.; PAULA, B. F.; SILVA, J. J.; COELHO, L. F. L.; SILVA, M.A.; MARQUES, V. B. B.; CHAVASCO, J. K.; SILVA, G. A. Chemical characterization and evaluation of antibacterial, antifungal, antimycobacterial, and cytotoxic activities of Talinum paniculatum. Revista do Instituto de Medicina Tropical, São Paulo, v. 57, n. 5, p.397-405, 2015. Disponível em: http://www.scielo.br/pdf/rimtsp/v57n5/0036-4665-rimtsp57-05-00397.pdf. Acesso em: 02 out. 2018.

SALlES, J. S.; STEINER, F.; ABAKER, J. E. P.; FERREIRA, T. S.; MARTINS, G. L. M. Resposta da rúcula à adubação orgânica com diferentes compostos orgânicos. Revista de Agricultura Neotropical, Cassilândia, v. 4, n. 2, p.35-40, 2017. Disponível em: http://periodicosonline.uems.br/index.php/agrineo/article/view/1450/1381. Acesso em: 05 out. 2018.

SANTOS, R. H. S.; SILVA, F.; CASALI, V. W. D.; CONDE, A. R. Efeito residual da adubação com composto orgânico sobre o crescimento e produção de alface. Pesquisa Agropecuária Brasileira, Brasília, v. 36, n. 11, p.1398-1398, 2001. Disponível em: http://www.scielo.br/pdf/\%0D/pab/v36n11/6813.pdf. Acesso em: 08 out. 2018.

SANTOS, G. M.; OliveIRA, A. P.; SIlvA, J. A. L.; AlVES, E. U.; COSTA, C. C. Características e rendimento de vagem do feijão-vagem em função de fontes e doses de matéria orgânica. Horticultura Brasileira, Brasília, v. 19, n. 1, p.30-35, 2001. Disponível em: http://www.scielo.br/pdf/\%0D/hb/v19n1/v19n1a06.pdf. Acesso em: 15 jul. 2019. 
SEDIYAMA, M. A. N.; MAGALhÃES, I. P. B.; VIDIGAL, S. M.; PINTO, C. L. O.; CARDOSO, D. S.; FONSECA, M. C. M.; CARVALHO, P. L. Uso de fertilizantes orgânicos no cultivo de alface americana (Lactuca sativa L.) 'kaiser'. Revista Brasileira de Agropecuária Sustentável, Viçosa, v. 6, n. 2, p.66-74, 2016. Disponível em: http://www.locus.ufv.br/bitstream/handle/123456789/17167/artigo.pdf?sequence=1. Acesso em: 08 out. 2018.

SHAHEIN, M. M.; AFIFI, M. M.; ALGHARIB, A. M. Assessing the effect of humic substances extracted from compost and biogas manure on yield and quality of lettuce (Lactuca sativa L.). American-Eurasian Journal of Agricultural \& Environmental Sciences, Faisalabad, v. 14, n. 10, p.996-1009, 2014. Disponível em: https://doi.org/10.5829/idosi.aejaes.2014.14.10.12415. Acesso em: 28 out. 2018.

SILVA, V. M.; TEIXEIRA, A. F. R.; SOUZA, J. L.; GUIMARÃES, G. P.; BENASSI, A. C.; MENDONÇA, E. S. Estoques de carbono e nitrogênio e densidade do solo em sistemas de adubação orgânica de café conilon. Revista Brasileira de Ciência do Solo, Viçosa, v. 39, n. 5, p. 1436-1444, 2015. Disponível em: http://www.scielo.br/pdf/asagr/v35n3/v35n3a01.pdf. Acesso em: 20 out. 2018.

THANAMOOL, C.; PAPIROM, P.; CHANLUN, S.; KUPITTAYANANT, S. Talinum paniculatum (Jacq.) Gaertn: a medicinal plant with potential estrogenic activity in ovariectomized rats. International Journal of Pharmacy and Pharmaceutical Sciences, Madhya Pradesh, v. 5, n. 2, p.478-485. 2013. Disponível em: https://www.researchgate.net/profile/Catthareeya_Sukwan/publication/237047324_Talinum_ paniculatum_Jacq_Gertn_A_medicinal_plant_with_potential_estrogenic_activity_in_ovariect omized_rats/links/0c96051b039c6da936000000/Talinum-paniculatum-Jacq-Gertn-Amedicinal-plant-with-potential-estrogenic-activity-in-ovariectomized-rats.pdf. Acesso em: 08 out. 2018.

UMEOKOLI, B. O.; MUHARINI, R.; OKOYE, F. B.; AJIWE, V. I.; AKPUAKA, M. U.; LIN, W.; LIU, Z.; PROKSCH, P. New C-methylated flavonoids and $\alpha$-pyrone derivative from roots of Talinum triangulare growing in Nigeria. Fitoterapia, Milano, v. 109, p.169-173, 2016.

Disponível

em: https://www.sciencedirect.com/science/article/pii/S0367326X16300028. Acesso em: 18 out. 2018.

VASCONCElOS, U. A. A.; COSTA, C. C.; OliveirA, M. N.; SIlVA, J. W. B.; MEDEIROS, A. B.; SOBRINHO, T. G. Efeito residual do esterco ovino no cultivo da alface em diferentes espaçamentos. Revista Verde de Agroecologia e Desenvolvimento Sustentável, Viçosa, MG, v. 12, n. 3, p.508-511, 2017. Disponível em: http://www.locus.ufv.br/bitstream/handle/123456789/18324/artigo.pdf?sequence=1\&isAllow ed=y. Acesso em: 04 out. 2018.

ZANDONADI, D. B.; SANTOS, M. P.; MEDICI, L. O.; SILVA, J. Ação da matéria orgânica e suas frações sobre a fisiologia de hortaliças. Horticultura Brasileira, Vitória da Conquista, v. $32, \quad$ n. $1, \quad$ p.14-20, 2014. Disponível em: 
https://www.alice.cnptia.embrapa.br/bitstream/doc/984124/1/Acaodamateriaorganicaesuasfra coessobreafisiologiadehortalicas.pdf. Acesso em: 08 out. 2018.

ZIECH, A. R. D.; CONCEIÇÃO, P. C.; LUCHESE, A. V.; PAULUS, D.; ZIECH, M. F. Cultivo de alface em diferentes manejos de cobertura do solo e fontes de adubação. Revista Brasileira de Engenharia Agrícola e Ambiental, Campina Grande, v. 18, n. 9, p.948-954, 2014. Disponível em: http://dx.doi.org/10.1590/1807-1929/agriambi.v18n09p948-954. Acesso em: 12 out. 2018. 